\title{
O MEIO TÉCNICO CIENTÍFICO INFORMACIONAL E O USO DO CINEMA NAS AULAS DE GEOGRAFIA: PROVOCANDO SITUAÇÕES DE APRENDIZAGEM
}

\section{The technical-scientific-information environment and the use of cinema in Geography classes: creating learning cases}

Prissilla Mello de Oliveira

Mestre em Geografia e Meio Ambiente pela PUC-RJ

prissillamello@yahoo.com.br

Artigo recebido em 18/09/2013 e aceito para publicação em 10/05/2014

DOI: $10.12957 /$ tamoios.2014.7460

RESUMO O uso do cinema em sala de aula não é novidade, mas mesmo sendo utilizado há algum tempo isso não significa que é sempre apropriado corretamente. Muitos professores adotam este recurso de forma irresponsável, apenas como uma alternativa por não ter preparado a aula ou como "passa tempo". No entanto, apesar de alguns problemas na utilização deste recurso, ele apresenta potencial enriquecedor da relação ensino aprendizagem. Neste sentido, também há professores que utilizam o cinema como um importante recurso que pode mediar as aulas de geografia e torná-las mais interessantes. O cinema, assim como outro recurso didático, deve ser trabalhado como muita responsabilidade, visto que atualmente ele é um importante formador de opiniões. No mundo atual a difusão de informações está cada vez mais intensa, mas isso não garante a fidelidade dos dados transmitidos. Sendo assim, é fundamental auxiliar os alunos na leitura de tal recurso. Analisar filmes em aula pode promover uma leitura menos superficial do mundo e garantir um avanço no processo de construção de conceitos geográficos.

Palavras-chave: cinema, ensino de geografia, aprendizagem, meio técnico científico informacional.

ABSTRACT The use of movie in the classroom is not new, but even being used for some time that does not mean it is always appropriate properly. Many teachers adopted this practice in an irresponsible manner, just as an alternative for not having prepared a lesson or as a "hobby." However, despite some problems in using this feature, it has potential for enriching the teaching and learning. In this sense, there are also teachers who use films as an important resource that can mediate the geography lessons and make them more interesting. The cinema, as well as other teaching resource, should be worked as much responsibility, as currently it is an important opinion maker. In today's world information dissemination is increasingly intense, but that does not guarantee the reliability of data transmitted. Therefore, it is essential to help students in reading such an action. Analyze films in the classroom can promote a less superficial reading of the world and ensure a breakthrough in the construction of geographical concepts.

Keywords: movie, geography teaching, learning. 


\section{INTRODUÇÃO}

O uso do cinema em sala de aula não é novidade, mas mesmo sendo utilizado há algum tempo isso não significa que é sempre apropriado corretamente. Muitos professores adotam este recurso de forma irresponsável, apenas como uma alternativa por não ter preparado a aula ou como "passa tempo". No entanto, apesar de alguns problemas na utilização deste recurso, ele apresenta potencial enriquecedor da relação ensino-aprendizagem. Neste sentido, também há professores que utilizam o cinema como um importante recurso que pode mediar as aulas de geografia e torná-las mais interessantes.

O cinema, assim como outro recurso didático, deve ser trabalhado com muita responsabilidade, visto que atualmente ele é um importante formador de opiniões. No mundo atual a difusão de informações está cada vez mais intensa, mas isso não garante a fidelidade dos dados transmitidos. Sendo assim, é fundamental auxiliar os alunos na leitura de tal recurso. Analisar filmes em aula pode promover uma leitura menos superficial do mundo e garantir um avanço no processo de construção de conceitos geográficos.

Sem a intenção de impor caminhos predeterminados, o objetivo do presente trabalho é indicar alternativas de se ensinar geografia na escola. Busca-se apontar situações de ensino-aprendizagem que superem o senso comum e a simples memorizações e descrição de fatos, características ainda muito presentes no ensino da geografia escolar. É fundamental destacar um processo de aprendizagem que seja construído pela conjunção dos conhecimentos prévios dos alunos, através de suas práticas espaciais, e os conceitos científicos. Neste sentido, o professor deve ser reafirmado como o mediador deste processo, pois necessita estar ciente de seus conhecimentos e ações.

As alternativas apresentadas aqui estão relacionadas à adoção de recursos áudio visuais, mais especificamente o cinema. Posto que, tal instrumento pode servir para uma interpretação crítica da organização do espaço. Sendo fundamental discutir o papel da escola e do ensino de Geografia mediante a atual fase do sistema capitalista, marcada pelo que Milton Santos (2008) chama de "meio-técnico-científico-informacional".

Dentre os autores centrais que norteiam a discussão relacionada ao processo de ensino-aprendizagem e a utilização de recursos como o cinema nas aulas de Geografia, estão: BARBOSA (2006); CASTELLAR e VILHENA, (2010); PONTUSCHKA et all (2007). Dentre os autores base para a discussão a cerca da atual difusão em massa das informações, marcada pelo "meio-técnico-científico-informacional", estão: SANTOS (2008); HARVEY (2007); DEBORD (1991), dentre outros.

$\mathrm{O}$ trabalho está dividido em 3 partes principais. Primeiramente será feito um breve resgate de algumas características do meio-técnico-científico-informacional e o papel da escola neste atual contexto, destacando a difusão da informação no mundo atual e a importância do professor e da escola na interpretação dessas informações. Em seguida será ressaltado de que maneira o cinema apresenta-se como um importante recurso para o ensino de Geografia. E por fim, será feita uma análise de dois longa metragens (Wall-e e Tapete Vermelho), onde será apresentada a possibilidade de se discutir o meio-técnico-científico-informacional, entre outros temas, pelas telas de cinema nas aulas de Geografia.

\section{O MEIO TÉCNICO-CIENTÍFICO-INFORMACIONAL E O PAPEL DA ESCOLA}

É necessário discutir como está a atual disseminação de informação pelo mundo, e consequentemente sua repercussão na interpretação do espaço geográfico pela sociedade. Faz-se imprescindível analisar qual o papel da escola e dos profissionais da educação (no caso deste trabalho, os professores de Geografia) na interpretação das 
informações difundidas. Destacando assim, a responsabilidade em auxiliar uma visão mais crítica dos fenômenos espaciais pelos alunos.

A sociedade atual está cada vez mais marcada pelo poder da informação, onde há uma revolução mais intensa dos meios de comunicação. Com a mudança do regime de acumulação capitalista - do fordismo para a “acumulação flexível” - ocorreu uma intensa modificação no paradigma tecnológico. A informação transformou-se em "mercadoria" fundamental para o capital. As empresas passaram a dar mais importância a fatores relacionados ao fluxo de informação, controle de técnicas, assim como as estratégias financeiras e de mercado. A sociedade ocidental entra no período em que Milton Santos denomina de "meio técnico científico informacional”.

Neste período, os objetos técnicos tendem a ser ao mesmo tempo técnicos e informacionais, já que, graças à extrema intencionalidade de sua produção e de sua localização, eles já surgem como informação; e, na verdade, a energia principal de seu funcionamento é também a informação. Já hoje, quando nos referimos às manifestações geográficas decorrentes dos novos processos, não é mais de meio técnico que se trata. Estamos diante da produção de algo novo, a que estamos chamando de meio técnico científico informacional. (SANTOS, 2008, p.238)

O movimento de racionalização da sociedade marcou várias fases da história até, pouco a pouco, ocupar todos os aspectos da vida social. Atualmente, esse movimento alcança um novo patamar, que se pode chamar de racionalização do espaço geográfico. Este atual patamar está intimamente relacionado à emergência do meiotécnico-científico-informacional, que tem buscado substituir o meio natural e o próprio meio técnico, produzindo espaços da racionalidade e constituindo-se base para as principais ações globalizadas.

Esta atual situação não tem garantido a formação de indivíduos críticos, visto que as informações que chegam à sociedade se apresentam de forma simplista e fragmentada, não estabelecendo relação com o conhecimento. As informações são controladas por grandes empresas do setor de mídia que a manipulam e a utilizam para atender aos interesses de mercado. A difusão de informações é um dos vieses da atual "sociedade do espetáculo". Segundo Guy Debord (1991) o espetáculo está diretamente relacionado ao modo de produção existente:

\begin{abstract}
O espetáculo, compreendido na sua totalidade, é ao mesmo tempo o resultado e o projeto do modo de produção existente. Ele não é um suplemento ao mundo real, a sua decoração readicionada. É o coração da irrealidade da sociedade real. Sob todas as suas formas particulares, informação ou propaganda, publicidade ou consumo direto de divertimentos, o espetáculo constitui o modelo presente da vida socialmente dominante. Ele é a afirmação onipresente da escolha já feita na produção, e o seu corolário o consumo. Forma e conteúdo do espetáculo são identicamente a justificação total das condições e dos fins do sistema existente. O espetáculo é também a presença permanente desta justificação, enquanto ocupação da parte principal do tempo vivido fora da produção moderna. (Debord, 1991, p. 17)
\end{abstract}

Há uma intensa gama de informações transmitidas pela mídia e pelas redes de computadores, neste sentido é necessário analisar cuidadosamente tais dados disponibilizados. A maior parte dessas informações vem de uma ordem global (vertical-distante). Tal ordem cria, no lugar, uma desordem, pois produz mudanças funcionais e estruturais. Esta ordem imposta verticalmente transforma a globalização, no atual estágio, em algo perverso para a maioria das pessoas. Já que seu objetivo, sua referencia e sua finalidade é o próprio mercado global. Esta ordem tem relação intrínseca com o domínio dos conhecimentos técnicos, dos códigos hegemônicos, conseguentemente do poder. Toda informação transmitida possui certa intencionalidade, e muitas das vezes essas informações são lançados ao público de forma desconexa, fragmentada e simplista.

A escola tem, neste contexto, o papel de apropriar-se dessas diversas formas de linguagem, decodificando, 
analisando e interpretando tais informações. É necessário auxiliar o aluno a desenvolver a capacidade de compreender e absorver as mudanças tecnológicas, visto que elas também se apresentam como novas formas de aprender.

O lugar onde o aluno vive seu dia-a-dia é marcado pela influencia desta ordem global, mas também é o espaço dominado pelas sensações, pela imaginação, pela emoção, pelos significados, onde esses elementos são incorporados ao viver diário. É nesta dimensão em que a verdadeira contestação pode ganhar terreno. Esses espaços são "parcelas" da forma como eles vivem o mundo, "parcelas" que envolvem a vida cotidiana, da mesma forma que afeta diretamente as experiências e as formas como se entende e interpreta as informações recebidas. É neste recorte territorial do fazer local, do espaço da contigüidade do cotidiano, chamado por Milton Santos (2008) de horizontalidade, que a ordem global se realiza. Há então nesta dimensão espacial a possibilidade de viabilizar e naturalizar a ação da ordem global (que vem de longe), como ao contrário, ocorre à possibilidade de se promover interpretações menos superficiais da realidade espacial, sendo possível até promover mudanças.

Neste sentido, para ler o mundo atual é necessário um processo constante de decodificação de mensagens, de articulação e contextualização das informações. Levando em consideração a influencia global (“distante”) e as experiências do cotidiano (do que é "próximo"). O aluno deve ser capaz de refletir sobre a realidade em várias escalas, promovendo uma visão articulada e organizada de mundo. È necessário tratar a informação para que ela se transforme em conhecimento.

O ensino escolar perde cada vez mais espaço para a influência de uma "cultura" de massa produzida pelo capital. Os diferentes níveis de acesso à informação e ao conhecimento intensificam as desigualdades sociais, já que aumenta a lacuna entre os indivíduos, ampliando, portanto, as diferenças de classe.

Segundo Pontuschka et all (2007), atualmente a gama de informações transmitidas pelos diversos meios de comunicação são demasiadamente amplas e desconexas. É necessário preparar o aluno para que ele desenvolva um senso crítico e saiba selecionar e utilizar tais informações da melhor maneira possível, para isso a escola é um importante meio de acesso à informação e ao conhecimento.

Segundo Castellar e Vilhena (2010), a partir de um conceito pode se chegar a outro(s) e também analisar as relações entre eles, ou seja, a vivência do aluno proporciona noções sobre o mundo teórico. Atrelado a isso há ações do docente problematizando, expondo, realizando trabalhos de campo, analisando informações difundidas pelos meios de comunicação, entre outros, que contribuíram para o aluno estruturar e construir conceitos científicos de caráter teórico.

É fundamental o elo entre o professor e o aluno, ou seja, a aula deve ser um diálogo entre esses dois atores, sendo uma aula que parta da experiência dos alunos e acrescente a explicação científica ao cotidiano. Bachelar (apud Castellar e Vilhena, 2010, p. 100) afirma que a dificuldade está em "colocar a cultura científica em estado de mobilização permanente".

A ligação entre a arte de ensinar e o que ensinar deve partir da relação entre a teoria (científica e escolar) e a prática. Para se construir um conceito é necessário que ele esteja dentro de um contexto. Sendo os conceitos idéias que se tem sobre determinados objetos ou fenômenos, eles estão no plano das idéias e são socialmente estabelecidos. Sendo assim, a construção de conceitos não é algo exclusivo da escola, visto que se constrói conceito a partir da vivência. As aulas práticas auxiliam o aluno na construção e mudanças conceituais. Há a necessidade de articular os conceitos, hierarquizá-los, relacioná-los e situá-los.

Utilizar recursos audiovisuais auxilia na ampliação do conceito e o relacionam com a realidade, alem de 
trazer outros tipos de linguagens para a sala de aula. Castellar e Vilhena (2010) deixam claro que a função do professor não é apenas auxiliar na construção dos conceitos e relacioná-los com outros, mas também organizar o material, selecionar filmes e imagens, sendo importante também que o vídeo seja discutido antes de acabar a aula. Ou seja, elaborar um plano de aula que estimule o aluno a participar do que está sendo proposto.

A partir da metodologia apontada pelas autoras é possível desenvolver um processo de aprendizagem e não de memorização. O sucesso das atividades elaboradas para a aula não está na parte quantitativa (número de tarefas) e sim na qualitativa (quais os objetivos.). Determinadas atividades podem levar ao entendimento de inúmeros conceitos, isto porque os conceitos resultam de fenômenos que estão interligados, e assim devem ser analisados.

A Geografia como disciplina escolar deve auxiliar o aluno na leitura e compreensão do espaço geográfico, entendendo este espaço geográfico como uma construção histórico-social, fruto de uma relação dialética entre configuração territorial e relações sociais. Sendo assim, a Geografia é uma das disciplinas que ajuda o aluno a compreender o mundo atual, pois discute diversas questões relacionadas as transformações que a sociedade vem passando em escala global e local. Neste sentido, é fundamental que o professor de Geografia saiba lidar com as diversas linguagens e tecnologias para utilizar, na medida do possível, com os alunos.

Várias são as linguagens que podem ser utilizadas como recursos nas aulas de geografia: filmes, documentários, músicas, histórias em quadrinhos, Internet, entre outros. É necessário transformar as aulas em momentos de crítica da realidade que nos assola e, ao mesmo tempo, torná-la um lugar para "sonhar com o mundo" (Barbosa, 2006:110).

\section{O CINEMA COMO RECURSO PARA O ENSINO DE GEOGRAFIA}

É fundamental discutir como e por que o cinema pode ser apropriado pelo professor de geografia em suas aulas.

O uso do cinema como recurso em sala de aula não é novidade. No entanto, segundo Pontuschka et al (2007) e Barbosa (2006), enquanto alguns professores utilizam este recurso adequadamente entendendo-o como forma de dinamizar as aulas, muitos o utilizam como: um "passa tempo", estratégia por não ter preparado a aula, alternativa para a falta de professor ou mesmo desconsiderando que o filme é composto por um todo integrado com o uso de diversas linguagens. "Esquecendo" que é um recurso que integra questões cognitivas, artísticas e afetivas de grande significado, se constituindo um importante formador de opiniões.

Tanto os filmes, quanto os documentários, músicas, programas de TV, reportagens, etc. funcionam para “formar opiniões", apresentando-se como importante e perigoso aparelho ideológico. Já que expressam o interesse de determinadas classes. Neste sentido, é fundamental que o professor produza um senso analítico e crítico junto com os alunos.

É interessante também que o professor apresente filmes, documentários e músicas (produções artísticas) que estão fora do circuito da cultura de massa produzida pelo grande capital. Segundo Douglas Kellner (apud REIS 2007):

A cultura da mídia é industrial; organiza-se com base no modelo de produção de massa e é produzida para a massa de acordo com tipos (gêneros), segundo fórmulas, códigos e normas convencionais. É, portanto, uma forma de cultura comercial, e seus produtos são mercadorias. (REIS, 2007, p. 2) 
Neste sentido, é necessário apresentar outras visões sobre determinados assuntos e fazer um retrospecto do filme apresentado, analisando os aspectos e conceitos relevantes à geografia e a educação. Deixando sempre claro que estes são representações sobre a realidade e que não existe neutralidade e imparcialidade ao contar uma história.

É importante selecionar filmes compatíveis com a programação da disciplina escolar e a formação psicosocial dos educandos, e posteriormente propor atividades que façam resgatar e refletir sobre o filme apresentado.

Segundo Barbosa (2006), o dialogo entre geografia e cinema tem sido bastante tímido. Ele afirma que os professores passaram a utilizar este recurso com mais frequência em sala de aula a partir da década de 1990.

O cinema tem uma relação intrínseca com o objeto da geografia. Segundo Pierre Francastel (apud Barbosa 2006), o cinema, ao contrário da literatura e da música, estabelece claramente a noção de espaço. Neste sentido, a relação cinema-geografia pode ser tímida, mas a relação cinema-espaço não é.

David Harvey (2007) apresenta como importantes temas para a geografia atual são representadas em obras cinematográficas pós-modernas. Segundo este autor, o cinema apresenta uma forte possibilidade de tratar temas relacionados ao espaço e ao tempo; é, dentre as formas artísticas, a mais capaz disso. O cinema teria esta capacidade devido a liberdade do uso de imagens, onde ocorre cortes no tempo e no espaço em qualquer direção. No entanto, o cinema também tem suas limitações, visto que é um "espetáculo projetado numa tela sem profundidade" (Harvey, 2007: 277).

Outras expressões artísticas como a música, histórias em quadrinhos, fotografias, por exemplo, também emprestam ludicidade as aulas, tornando-as mais atrativas e interessantes. Contudo, o filme tem movimento e aproxima-se mais da nossa realidade, já que representa um espaço geográfico mesmo que artificial (irreal). Segundo Walter Benjamin (apud BARBOSA 2006), o cinema apresenta uma imagem muito significativa de real, mais do que qualquer outro meio. Isso ocorre, principalmente, devido ao modo como o homem se representa e representa o mundo através do cinema. O imaginário e o real se confundem no cinema.

Ainda segundo Barbosa (2006), o filme não deve ser utilizado para exemplificar ou reforçar o que foi explicado pelo professor, este tipo de abordagem reduziria este recurso a um "mero questionário de luxo". O papel do filme seria, na verdade, o de provocar uma situação de aprendizagem tanto para os alunos como para os professores. Deve estar relacionado à criação de indivíduos que produzem conhecimento e reconhecimento de si e do mundo.

Barbosa, com base em Walter Benjamin, classifica o cinema como técnica de reprodução que promove uma transformação nas relações da sociedade com a arte. O cinema estaria, então, diretamente ligado a uma reprodução técnica, que transforma a forma de fazer, entender e se relacionar com a arte. De acordo com Barbosa, esta idéia romântica de Benjamin é criticada por autores como Adorno e Horkheimer. Tais autores não vêem o cinema como expressão artística, pois o entendem como uma técnica exterior à obra de arte, que promoveria a homogeneização cultural (apud BARBOSA 2006). Seria então uma técnica que "destruiu" a obra de arte e favoreceu a racionalidade econômica do capitalismo, servindo de estratégia ideológica para tal sistema. Barbosa questiona quais desses autores estariam com a razão. Ele ressalta que o importante é que esses autores levantam questões interessantes sobre o cinema: técnica e arte; obra e mercadoria; ambigüidade e contradição.

É inegável que o filme promove um "bombardeio" de imagens que parece às vezes substituir a realidade pela representação da ficção, sendo uma prática social repleta de intencionalidade. Sendo assim, o cinema pode 
tanto contribuir para a superação da objetividade do nosso dia a dia como nos prender em um universo de representações.

\begin{abstract}
A intencionalidade do universo simulacional, enquanto prática social, exercita um poder disciplinar sobre o nosso imaginário e esgota, na própria imagem, as possibilidades de apropriação do mundo e, como conseqüência imediata, provoca a substituição da experiência pela representação de representações. Essa fissura entre o cultural e o social impõe novos desafios à interpretação do nosso ser e estar no mundo e, sema menor dúvida, à própria construção do conhecimento e suas formas de socialização. (BARBOSA, 2006, p. 112)
\end{abstract}

O cinema pode, então, ser analisado do ponto de vista da produção de imagens, pois a interpretação de imagens é uma das formas de leitura e de entendimento do mundo. A imagem serve muitas das vezes como ponto de partida para a análise de determinado espaço, por isso elas devem ser cuidadosamente observadas e interpretadas, visto que a sua superficialidade pode levar-nos ao erro. No ensino de Geografia as imagens devem servir de complementação do texto, de onde é possível extrair informação, articulando-a ao conteúdo escrito. As imagens são importantes meios de informação e não devem ser entendidas ou aplicadas apenas como simples ilustração.

Do ponto de vista da produção de imagens, o cinema pode ser entendido como um sistema complexo que incorpora tanto tecnologias como "discursos" da câmera, da iluminação, da edição, do cenário e do som (Turner, 1997)- que contribuem para a constituição de imagens do mundo. Então, podemos afirmar que a representação fílmica cria corpos visíveis, porém imaginários, que possuem como referentes imediatos ou distantes, os corpos reais. Estes, por sua vez, nem sempre são perceptíveis como base ou fonte original das imagens. (BARBOSA, 2006, p. 114)

Indagar a partir das imagens cinematográficas questões relativas as discussões geográficas requer um certo cuidado. Segundo D. Bernard, P. Farges e P. Wallet (apud BARBOSA 2006), a leitura da imagem cinematográfica do ponto de vista geográfico deve considerar:

- a autenticidade das paisagens representadas;

- o etnocentrismo e os arquétipos de figuração;

- a subjetividade do autor na narração e na escolha dos enquadramentos do espaço representado.

Segundo Claude Collin-Delavaud (apud BARBOSA 2006), muitos filmes pecam na veracidade dos lugares e histórias representadas. O professor de Geografia tem que estar atento a este fator. Muitas vezes as técnicas de reprodução promovem uma cópia da realidade que se afasta do objeto original, sendo esse afastamento, muitas das vezes, intencional. Neste sentido, o professor de geografia tem que evitar organizar suas analises a partir da aparência imediata do real, pois assim corre-se o risco de perder a complexidade sob a qual são construídos as "imagens do mundo e o mundo das imagens". Deve-se ir alem da análise das imagens, visto que o importante são as relações estabelecidas entre os personagens (relações estas que produzem e são produtos do espaço social, mesmo que artificial).

Muitos filmes incorrem no "erro" de produzir concepções homogeneizantes do mundo, através da criação de estereótipos e clichês. Vários filmes de caráter etnocêntrico satirizam e fazem caricaturas grotescas de outros povos, tentando demonstrar um padrão "correto" para ser seguido pela sociedade.

Nas imagens veiculadas por vários filmes de ficção, e até mesmo em documentários, diversas sociedades são expostas por meio de leituras redutoras e reprodutoras de preconceitos que 
variam dos mais sutis aos mais grosseiros. Elas reificam as sociedades que não partilham dos mesmos valores e objetivos da matriz ocidental e as condena, invariavelmente, à condição de "fora da humanidade". (BARBOSA, 2006, p. 120)

Filmes e documentários que produzem estereótipos visam reproduzir o domínio cultural etnocêntrico. Tais filmes excluem as relações sociais do seu contexto espacial, e produzem imagens desconexas da história. As caricaturas e leituras exóticas também se espantem para as paisagens de determinados lugares do mundo. No entanto, como os alunos tem um grande acesso a maioria desses filmes com leituras etnocêntricas, temos a obrigação de utilizá-los nas aulas, com objetivo de analisá-los criticamente. Alem disso, eles podem, de alguma forma expressar conflitos sociais como afirma Douglas Kellner (apud REIS 2007):

\begin{abstract}
Enquanto a cultura da mídia promove os interesses das classes que possuem e controlam os grandes conglomerados dos meios de comunicação, seus produtos também participam dos conflitos sociais entre grupos concorrentes e veiculam posições conflitantes, promovendo, às vezes, forças de resistência e progresso. Conseqüentemente, a cultura veiculada pela mídia não pode ser rejeitada como um instrumento banal da ideologia dominante, mas deve ser interpretada e contextualizada de modos diferentes dentro da matriz dos discursos e das forças sociais concorrentes que a constituem. (Kellner apud REIS, 2007, p. 3)
\end{abstract}

Mas é fundamental também apresentar filmes (alternativos) que contrapõem as idéias propagadas pelos grupos dominantes.

Quando se aborda determinada cultura ou lugar é interessante procurar filmes produzidos pelos povos retratados na película, e não leituras exteriores. A imagem hollywoodiana do Brasil, por exemplo, é altamente caricata. Apesar de também existirem produções brasileiras que seguem a linha caricata hollywoodiana, mesmo assim é mais interessante utilizar filmes nacionais para falar do Brasil.

É necessário reforçar, novamente, a idéia de que nenhum filme é neutro, visto que ele surge dentro do imaginário social. Segundo Barbosa (2006), as narrativas dos filmes estão ligadas a vários fatores: proposições estéticas, a trama do roteiro, as exigências das corporações financiadoras, assim como a concepção de mundo do realizador. Este último fator fica evidente devido ao maior ou menor caráter estereotipado dos sujeitos representados. Como afirma HARVEY (2007), a forma como se representa o espaço está diretamente relacionado ao modo como o ser humano interpreta e age sobre o mundo.

A linguagem do cinema, como uma produção cultural, pode e deve ser utilizada em aula, pois amplia os horizontes intelectuais para a análise do mundo. Sendo assim, é fundamental que os professores conheçam esta linguagem, na medida em que ela é decorrente da integração de diversas linguagens. O professor ao passar um filme em sala de aula tem que ter claro os objetivos desta atividade, para que não ocorra o desconforto do filme parecer como uma mera distração para os alunos, completamente desconexo das aulas de geografia.

\title{
O MEIO TÉCNICO-CIENTÍFICO NAS TELAS DO CINEMA
}

A seguir apresenta-se a análise de dois filmes que podem servir como mediadores para o desenvolvimento de diversos conteúdos da geografia, visto que estão diretamente ligados a noção de tempo e espaço de questões sociais, econômicas, políticas e ambientais.

Os filmes apresentam perspectivas e mensagens diferentes, mas ajudam a refletir e mediar diversos conteúdos aplicados à geografia escolar. Os filmes escolhidos para esta análise são:

1. Longa-metragem animado Norte Americano "Wall-E".

2. Longa metragem nacional "Tapete Vermelho". 
1- Wall-E. Direção e roteiro de Andrew Stanton. Disney/Pixar, 2009 (98 min.)

Este longa-metragem infantil pode ser analisado por diversos prismas, podendo ser trabalhado em conjunto com professores de outras disciplinas (biologia, história, sociologia, português, etc) na perspectiva interdisciplinar. Tal filme permite enfatizar diversas questões eminentemente geográficas. Através dele é possível enfocar vários aspectos como as questões ambientais, sociais, políticas e econômicas da pós-modernidade.

Já no primeiro momento, o filme apresenta elementos interessantes para análise, através da imagem do planeta Terra vista do espaço, uma imagem opaca (sem cor) e com uma camada de poluentes na atmosfera. A câmera vai aos poucos se aproximando da superfície e a situação não melhora. Pilhas e mais pilhas de lixo cobrem a superfície em meio a prédios e construções abandonadas, sempre em cores opacas (sem vida). Não é possível ver estrelas no céu e explosões ocorrem periodicamente. A Terra apresenta-se humanamente inabilitada. A introdução do filme sugere questões referentes às transformações provocadas pela interferência humana, que se vê fora da natureza (a questão da degradação ambiental pode ser trabalhada). Alem disso, há a possibilidade de estimular uma tentativa de construção dos conceitos de paisagem e espaço geográfico, desconstruindo a idéia de que paisagem é somente aquilo que é bonito e de que este conceito é sinônimo de espaço geográfico. O filme apresenta uma paisagem extremamente modificada pela ação humana, logo uma paisagem humanizada, no entanto não apresenta um espaço geográfico, visto que este necessita de relações humanas (sociais) para existir. Segundo Santos (2008: 83), a "paisagem é o conjunto de formas que, num dado momento, exprimem as heranças que representam as sucessivas relações localizadas entre homem e natureza. O espaço são essas formas mais a vida que as anima".

Em meio a esta sena "deserta" aparece Wall-e, o protagonista do filme e o único "habitante" do planeta. Wall-E faz parte de uma classe de robôs criada para remover e empilhar o lixo da Terra para que ela possa voltar a ser habitável. No entanto, o ambiente inóspito da Terra estraga os Wall-Es, sobrando apenas um (o protagonista). O robô remanescente utiliza como fonte de energia a luz solar e prossegue realizando todas as atividades para a qual ele fora programado, e também acaba desenvolvendo consciência e personalidade.

Ao longo do filme revela-se que os Wall-Es foram criados pela mega companhia BNL (Única empresa do mundo cujo "dono" também é um tipo de "presidente" do mundo). Tal mega companhia promove, aos seres humanos, um cruzeiro de 5 anos pelo espaço a bordo da nave Axiom, enquanto os Wall-Es se encarregam de limpar a Terra. No entanto o projeto não funciona, visto que a vida na Terra se torna insustentável e o cruzeiro acaba por se estender por mais de 700 anos. A BNL pode render discussões acerca das grandes multinacionais que dominam os mercados mundiais, da condição pós-moderna da organização da economia baseada, dentre outras coisas, no intenso avanço tecnológico e no domínio da informação como fonte de poder.

Em meio aos escombros e as pilhas de lixo, Wall-E encontra uma planta: "recurso natural renovável" que foi destruído devido ao modo como foi apropriado; sugerindo discutir o conceito da natureza como recurso.

Em um dia como outro qualquer, chega a Terra a EVA (Examinadora de Vegetação Alienígena), um robô feminino mais moderno, cujo objetivo é procurar exemplares de vegetais vivos, o que seria um indício de que a vida na Terra teria se tornado sustentável novamente. Aos poucos Wall-E se aproxima de Eva e acaba se apaixonando.

No entanto, sua felicidade dura pouco. Ao mostrar o espécime vegetal para Eva a mesma "desliga-se"; dias depois uma nave vem buscá-la para levá-la a estação espacial AXIOM. Wall-E agarra-se na nave e também é levado para a estação. 
Ao chegar à estação espacial Axiom, Wall-E encontra um ambiente altamente robotizado. É interessante discutir a influência da $3^{\circ}$ revolução industrial e o conceito de meio-técnico-científico-informacional, onde há, entre outras coisas, um avanço significativo da ciência e da tecnologia voltada para informática, robótica, telecomunicações e biotecnologia. Alem disso, é interessante discutir o mito do fim do trabalho humano.

É neste ambiente que aparecem os primeiros seres humanos da história. Estão todos completamente envolvidos pelo mundo virtual promovido pela Axiom. Eles só se comunicam via um tipo de tela virtual (semelhante a um laptop) onde marcam encontros, festas, passeios, jogos, etc, mas sempre virtuais. Não fazem nenhum tipo de esforço físico, são transportados de lado a outro por um tipo de cadeira flutuante. São todos extremamente obesos, passam o dia comendo e em contato virtual. Vestem-se iguais e só trocam de roupa quando a Axiom "dita" uma nova moda. Eles não percebem o que há a sua volta, pois vivem completamente envolvidos por esta vida virtual e artificial. Wall-E ao desligar a tela virtual de uma mulher a faz perceber o lugar onde se encontra. Uma frase simples exprime o grau de "transe": "eu não sabia que tinha piscina", sendo esta a principal área por onde as cadeiras passam.

A vida humana na nave permite questionar a sociedade atual, completamente envolvida pelos espaços virtuais, pela alta tecnologia, por uma forte alienação produzida pelo sistema, etc. É interessante deixar que os alunos identifiquem na ficção semelhanças com suas vidas. O filme apresenta uma crítica a crescente apatia dos seres humanos, que, automatizando sua vida em busca de uma aparente praticidade, tornam-se cada vez mais apáticos em suas atitudes. Desta forma, existe uma inversão de valores no filme: os robôs têm sentimentos, enquanto os humanos só fazem perdê-los.

De volta à aventura: o comandante da nave recebe a notícia de que EVA encontrou um espécime com fotossíntese, sendo este um indício de que a Terra teria novamente um estado de vida sustentável e poderia ser recolonizada. Ao decidir voltar para a Terra, o comandante descobre que o piloto automático e os robôs comissários da Axiom não permitiram este retorno devido a diretriz A-113, que receberam quase 700 anos antes enviada pelo presidente da BNL. Tal diretriz dá autonomia ao piloto automático dizendo para não permitir o retorno a Terra, visto que a vida se tornou definitivamente insustentável.

Em meio a vários contratempos, sendo perseguidos pela tropa robotizada da Axiom, Wall-E e EVA com a ajuda do comandante e de outros robôs conseguem colocar a planta em um holo-detector, que faz a nave localizar e ir á Terra. Ao longo desta aventura, Wall-E é gravemente "ferido" e pára de funcionar. Quando a Axion finalmente retorna, EVA voa até a suposta casa de Wall-E (um caminhão) onde existem as peças sobressalentes para o robô. EVA reativa Wall-E que não a reconhece a princípio, mas logo depois retoma a consciência. As cenas finais do filme mostram os homens com a ajuda dos robôs reconstruindo a vida na Terra.

O filme é sugestivo e interessante. Pode mediar vários conteúdos da Geografia escolar. Leva o aluno a refletir sobre vários temas como: a questão ecológica, o consumismo, a alienação, a produção cultural, econômica e social da pós modernidade, os conceitos de paisagem, espaço geográfico, meio natural e, principalmente, o de meio-técnico-científico-informacional. É fundamental também enfatizar a relação entre o homem e a natureza, fazendo, com base em Moreira 2006, a crítica a estrutura N-H-E (homem-natureza-economia), onde o homem é visto como algo desconexo da natureza e da sociedade (fora do tempo e do espaço). A crítica ao modelo N-H-E se inicia então por esta ideia de homem atópico, ou seja, aquele que vê a natureza e a sociedade como algo externo a ele. 
Por ser uma animação pode emprestar mais ludicidade a aula. Alem de conversar sobre o filme durante e depois da apresentação, é fundamental desenvolver atividades que o envolvem. Uma das atividades sugeridas é pedir para os alunos, em grupos, elaborarem uma continuação em história em quadrinho sobre o filme, assim como produzir letras de música ou pinturas relacionadas à história do filme.

2-Tapete Vermelho. Direção: Luiz Alberto Pereira. Roteiro: Luiz Alberto Pereira e Rosa Nepomuceno. Brasil, 2006 (102 $\mathrm{min})$.

A produção nacional se passa na atualidade e conta a saga de uma família do interior paulista que sai em busca de assistir um filme do Mazaropi no cinema. O filme apesar de ser um pouco caricato no que tange a representação do homem do campo, pode ser um importante elemento para se trabalhar nas aulas de Geografia. Aborda diferenças entre o meio rural e urbano, as transformações do meio rural, as desigualdades sociais, a reforma agrária, a valorização do homem do campo e de sua cultura, a refuncionalização do espaço, a crítica ao mercado de exibição cinematográfica monopolizado por filmes norte americanos, etc.

O filme inicia no sítio de Quinzinho, Zumira e Neco (protagonistas), localizado em Formoso, pequena cidade do Vale do Paraíba - interior Paulista. O meio rural pode ser percebido tanto pela paisagem, sem grandes transformações, como pelos sons (aspectos invisíveis do espaço geográfico). Iniciar a análise pela paisagem é muito importante, mas não devemos ficar restrita a ela, pois o que importa são as relações sociais.

Já no início do filme Quinzinho faz uma reflexão sobre as modificações da "roça" (meio rural), ele faz referência a diminuição das rãs no rio, pois, segundo ele, elas preferem água limpa (questão ambiental) e diz que tudo muda menos a vida do trabalhador. Em uma das cenas iniciais, ensina o filho Neco a pescar, demonstrando a necessidade da calma para plantar, colher e pescar, característica dos homens de tempo lento que Santos (2006) menciona.

O enredo do filme começa quando Quinzinho resolve cumprir uma promessa feita ao pai de levar o filho Neco para assistir um filme do Mazaropi no cinema; leva também a sua esposa Zumira (que vai contrariada) e o burro de estimação (Policarpo). Em sua viagem, rumo as cidades do interior paulista, percebe-se a mudança nas paisagens e nas relações entre as pessoas.

Antes de chegar a cidade mais próxima param em um sítio onde passam a noite. Destaca-se um céu extremamente estrelado e grupos cantam e dançam músicas sertanejas a beira da fogueira. Há, durante o filme, uma modificação gradativa das paisagens e costumes. No dia seguinte seguem rumo a cidade.

Ao chegar à cidade mais próxima do sítio descobrem que o antigo cinema mudou de função, virando uma loja. A discriminação contra o homem do campo começa a aparecer já nesta pequena cidade, através dos olhares e comentários dos moradores. Um dos vendedores da loja faz a seguinte interrogação: "Para que caipira quer cinema?", depois tenta vender uma televisão para Quinzinho. Quinzinho recusa a TV, diz que quer mesmo ir ao cinema e insinua que o vendedor nem sabe o que é cinema. O vendedor o chama de "Jeca" e diz que ele tem mesmo é que cuidar de sua plantação de batatas. Quinzinho responde: “-Sou Jeca sim senhor com muito gosto. Tenho minha terrinha, tenho o meu inhame, não é batata não. Trabalho para mim, não sou empregado como você”. Quinzinho e a família seguem viagem e descobrem que na próxima cidade a estrutura material do cinema também mudou de função virando um supermercado.

No caminho para outra cidade, Quinzinho, Zumira e Neco conhecem Manoel Pinto (O Mané Charreteiro) membro do MST (movimento dos sem terra). Mané Charreteiro diz terem encontrado uma grande fazenda 
improdutiva, seu objetivo é montar um pequeno rancho e viver da plantação. Relata sobre a contradição entre as várias famílias acampadas e o grande fazendeiro que tem vários latifúndios espalhados por todo o Brasil. Quinzinho diz que só não o acompanha por que já tem um pedaço de chão para viver. Conversam sobre a ação dos movimentos sociais que precisam pressionar o governo para promover a reforma agrária. Ao falar sobre o acampamento Quinzinho afirma: “- pouca gente com terra de mais, muita gente sem terra nenhuma, qual a novidade? É assim desde que o mundo é mundo". Manoel Charreteiro conta que não tem onde morar, que trabalhava em uma fazenda próxima (onde nasceu e criou-se), mas com a chegada das máquinas ele e outros ficaram sem emprego. Ele também diz que quando os fazendeiros precisam de mão de obra contratam temporariamente os bóias-frias da cidade. E afirma que se for para a cidade grande vai passar fome como muitos outros, pois não conseguem arrumar serviço. Esta passagem do filme dá margem para várias discussões referentes à modernização do campo, distribuição de terras no Brasil, desigualdade social, reforma agrária, movimentos sociais.

Ao chegar na próxima cidade vão almoçar em um restaurante a quilo. Ao pesar a refeição que dá cerca de 25 reais, Quinzinho questiona que é o preço de cerca de 10 cestos cheios de inhame. Eles valorizam muito a refeição e Zumira diz que o povo da cidade é um "bando de bocó que gasta todo o dinheiro em roupa”. Após a refeição descobrem que mais um cinema mudou de função, virando Igreja evangélica.

Seguem o passeio que acabou virando uma saga em busca de um cinema. É interessante destacar a falência das pequenas salas de cinema no Brasil a partir da década de 1970 e 1980 com a entrada das grandes empresas. Quando finalmente eles chegam em uma cidade que tem cinema, o funcionário os informa que lá só passa filme novo, ou seja, eles não exibem os filmes do Mazaropi.

Quinzinho resolve ir a um bar, onde encontra um famoso violeiro. O violeiro dá uma pequena aula de história, dizendo que as terras do Vale do Paraíba é por onde passavam as tropas carregadas de ouro de Minas Gerais em direção a Parati. Ele também diz que essas cidades foram muito ricas no tempo dos barões de café, mas que depois da queda do café os fazendeiros quebraram e as cidades ficaram "mortas" (esquecidas). Quinzinho responde: “- se é morta eu não sei não, por que tem bastante gente viva lá”. É muito interessante localizar esta região no mapa.

Rumo a próxima cidade conhecem um vigarista que os engana e rouba o Policarpo. Quinzinho e a família acabam parando no acampamento do MST em busca do filme do Mazaropi. Lá reencontram Mane Charreteiro e assistem um vídeo sobre a ação do MST em Brasília. Durante a exibição do vídeo o "dono” da fazenda chega com a polícia. Durante o conflito a polícia mata Mané Charreteito, Quinzinho é preso como arruaceiro e Neco desaparece. Zumira fica sozinha e é informada que o filho deve ter sido levado para a cidade de São Paulo.

Na delegacia Quinzinho diz não estar com os documentos, pois nunca precisou usar onde mora. Durante o interrogatório, alguns padres chegam e afirmam que a ação da polícia foi ilegal e Quinzinho é solto.

Ao ser solto, Quinzinho descobre que Neco sumiu e resolve ir a Aparecida fazer uma promessa para recuperar o filho. Pega carona com um caminhoneiro que relata sobre as desigualdades sociais e as grandes extensões de terras paradas ao longo do território brasileiro. Quinzinho afirma: “os ricos só enxergam os pobres quando eles estão atrapalhando demais". E o caminhoneiro completa: “- os sem terra só conseguiram algo quando aprenderam a fazer barulho".

Ao sair de Aparecida Quinzinho vai a cidade de São Paulo tentar encontrar o filho, enquanto Zumira espera na casa de um parente no grande centro urbano. Nesse momento a mudança da paisagem é significativa, 
saíram de um pequeno sítio, passaram por pequenas cidades e chegaram a um das maiores cidades brasileiras. A análise da transformação da paisagem ao longo é história é fundamental.

Quinzinho ao chegar em São Paulo entra em uma Igreja que também já tinha sido um cinema. Ganha umas latas de filme do Mazaropi e anda desolado pelas ruas na esperança de achar o filho. Enquanto isso, Neco comemora seu aniversário com crianças de rua, mas sente muita falta dos pais. Quinzinho desesperado, pára em frente a um cinema e chora a perda do filho que por milagre aparece. E a família consegue se reunir novamente.

A família retoma a busca pelo filme do Mazaropi, Quinzinho e Neco vão até um cinema onde são humilhados pelos funcionários que se recusam a passar o filme do Mazaropi. O funcionário ainda diz que só falta ele pedir para colocarem um tapete vermelho. Quinzinho se descontrola e é retirado do cinema pelo filho.

Quinzinho lembra do vídeo que viu no acampamento, compra algumas correntes e cadeados e se acorrenta na entrada do cinema como protesto. Se recusa a sair até que passem o filme do Mazaropi, diz que não passou por tudo para voltar para a roça sem darem atenção para ele. Por esta ação ele ganha destaque e aparece na televisão, é quando o dono do cinema aparece e permite que o filme seja passado como sessão especial. Quinzinho exige mais, agora ele também quer um tapete vermelho. Quinzinho e a família finalmente assistem ao filme do Mazaropi.

O filme, dentre outras coisas, demonstra bem a ação e a importância do que Milton Santos (2008) chama de "homem lento". Pois os "homens lentos" (personificados aqui pelo Quinzinho) não conseguem (ou não podem) estar o tempo todo em contato com as imagens produzidas por uma globalização perversa, por isso eles conseguem, de alguma forma, ver alem da racionalidade imposta. Explicitando também a tensão entre as forças hegemônicas (da ordem global/ verticalizada) e as lutas a favor de outra ordem mundial (que estão na ordem mais local, horizontal).

De volta ao sítio em Formosa, Quinzinho comunica a Zumira que terão que voltar a Aparecida para pagar a promessa de encontrar Neco, mas Zumira diz que nunca mais sairá da roça. O filme termina mostrando a influência dos costumes da cidade nos hábitos de Neco, que pede refrigerante, mas é reprimido pela mãe que diz que lá ele tomará mesmo uma limonada fresquinha.

Um filme interessante que pode ser utilizado em vários aspectos: pelos diálogos, pelas paisagens e pela história envolvente que, de forma leve, apresenta diversos temas que podem mediar vários conteúdos da geografia escolar.

A atividade proposta, além da discussão sobre o filme durante e após a exibição, é dividir a turma em grupos e distribuir falas significativas que aparecem ao longo do filme para eles discutirem em grupo e depois com toda a turma. Após fazer o debate, pedir para que eles escrevam individualmente uma redação sobre os pontos relevantes percebidos por eles no filme.

Os filmes selecionados para análise possuem temáticas bem diferentes, mas que auxilia na leitura do mundo e do meio-técnico-científico e suas contradições, confrontando sujeitos hegemônicos e resistentes a esta ordem mundial; demonstrando a relação possível entre cinema e o ensino de geografia.

\section{CONSIDERAÇÕES FINAIS}

Percebe-se que atualmente os estudantes estão inseridos em um mundo onde, entre outras coisas, a informação ganha destaque e se expande de forma rápida e desordenada através de diversos meios de comunicação, como: a televisão, o cinema, o rádio, a Internet, entre outros. Esses recursos podem ser utilizados 
para auxiliar o aluno a compreender o mundo em que vive. Não se deve encará-los como inimigos da educação, mas sim como recursos a serem utilizados a favor do trabalho pedagógico. É evidente que muitos desses meios de obter informações não são confiáveis, apresentam informações repetidas, fragmentadas e com forte caráter intencional.

Neste contexto, o professor tem um papel importante em auxiliar o aluno a transformar a informação em conhecimento, mediando a relação entre aluno e a mensagem recebida. Assim, é fundamental elaborar propostas que auxiliem na produção do conhecimento no espaço escolar.

Destacou-se assim a importância da variação de recursos para ler o mundo, em especial a cinematográfica, que nas condições socioculturais atuais tem invadido nossas vidas impondo novos modos de vida e formas de pensar. É fundamental que o aluno seja capaz de pensar sobre determinado assunto, contextualizar, estabelecer relações, etc. Ou seja, que eles desenvolvam os mecanismos necessários para analisar criticamente as informações que recebem dos diversos meios de comunicação.

A relação da geografia com o cinema pode contribuir para superar a nossa situação passiva perante as representações. Alem de tornar as aulas mais interessantes e atrativas.

Neste sentido, O presente texto buscou indicar um caminho pra tornar a relação ensino-aprendizagem mais interessante. Muitos outros caminhos são possíveis e necessários, o que faz a diferença é a responsabilidade e o amor para trilhá-los. É lógico que existem muitos problemas relativo às condições escolares que oferecem barreiras, mas elas não devem ser encaradas como barreiras intransponíveis, pois imaginá-las assim limita a ação já na sua gênese.

\section{REFERÊNCIAS BIBLIOGRÁFICAS}

BARBOSA, Jorge Luiz. Geografia e cinema: em busca de aproximações e do inesperado. In: CARLOS, Ana Fani Alessandri (Org.). A Geografia na sala de aula. São Paulo: Contexto, 2006. p.109-131.

CASTELAR, Sônia; VILHENA, Jerusa. "O significado da construção dos conceitos". In: "Ensino de geografia". São Paulo: Cengage Learning, 2010; p. 99-118.

DEBORD, Guy. A sociedade do espetáculo. Tradução de B. A. (1991)- k.1asphost.com

HARVEY, David. O tempo e o espaço no cinema pós moderno. In: HARVEY, David. Condição pós-moderna. Uma Pesquisa sobre as Origens da Mudança Cultural. São Paulo, Edições Loyola, 2007. p.277-289.

MOREIRA, Rui. Para onde vai o pensamento geográfico? Por uma epistemologia crítica. São Paulo: Contexto, 2006. P.101-132.

PONTUSCHKA, N. N; PAGANELli, T, I; CACETE, N. H. A linguagem cinematográfica no ensino de Geografia. In: PONTUSCHKA, Nídia N. (et all). Para ensinar Geografia. 1ºed. São Paulo: Cotez, 2007.p. 261 -286.

REIS, João M. da S. P.. O Pluralismo de Sentidos da Cultura da Mídia Contemporânea. IN: Intercom - Sociedade Brasileira de Estudos Interdisciplinares da Comunicação. XXX Congresso Brasileiro de Ciências da Comunicação - Santos - 29 de agosto a 2 de setembro de 2007.

SANTOS, Milton. A natureza do espaço - técnica e tempo, razão e emoção/ Milton Santos.-4.ed.4.reimpr.- São Paulo: Editora da Universidade de São Paulo, 2008.

\section{BIBLIOGRAFIA DOS FILMES ANALISADOS}

TAPETE VERMELHO. Direção: Luiz Alberto Pereira. Roteiro: Luiz Alberto Pereira e Rosa Nepomuceno. Brasil, 2006 (102 $\mathrm{min})$.

WALL-E. Direção e roteiro de Andrew Stanton. Disney/Pixar, 2009 (98 min). 